\title{
Effect of Fiber Geometry and Representative Volume Element on Elastic and Thermal Properties of Unidirectional Fiber-Reinforced Composites
}

\author{
Siva Bhaskara Rao Devireddy and Sandhyarani Biswas \\ Department of Mechanical Engineering, National Institute of Technology Rourkela, Rourkela 769008, India \\ Correspondence should be addressed to Siva Bhaskara Rao Devireddy; sivabhaskararao@gmail.com
}

Received 30 July 2014; Revised 22 September 2014; Accepted 27 October 2014; Published 18 November 2014

Academic Editor: Yanqing Yang

Copyright (C) 2014 S. B. R. Devireddy and S. Biswas. This is an open access article distributed under the Creative Commons Attribution License, which permits unrestricted use, distribution, and reproduction in any medium, provided the original work is properly cited.

\begin{abstract}
The aim of present work is focused on the evaluation of elastic and thermal properties of unidirectional fiber-reinforced polymer composites with different volume fractions of fiber up to $0.7 \mathrm{using}$ micromechanical approach. Two ways for calculating the material properties, that is, analytical and numerical approaches, were presented. In numerical approach, finite element analysis was used to evaluate the elastic modulus and thermal conductivity of composite from the constituent material properties. The finite element model based on three-dimensional micromechanical representative volume element (RVE) with a square and hexagonal packing geometry was implemented by using finite element code ANSYS. Circular cross section of fiber and square cross section of fiber were considered to develop RVE. The periodic boundary conditions are applied to the RVE to calculate elastic modulus of composite. The steady state heat transfer simulations were performed in thermal analysis to calculate thermal conductivity of composite. In analytical approach, the elastic modulus is calculated by rule of mixture, Halpin-Tsai model, and periodic microstructure. Thermal conductivity is calculated analytically by using rule of mixture, the Chawla model, and the Hashin model. The material properties obtained using finite element techniques were compared with different analytical methods and good agreement was achieved. The results are affected by a number of parameters such as volume fraction of the fibers, geometry of fiber, and RVE.
\end{abstract}

\section{Introduction}

There has been a considerable increase in the use of fiber composite materials in various industries like aerospace, automotive, infrastructures, and sporting goods due to their specific properties like strength, stiffness, toughness, high corrosion resistance, high wear resistance, high chemical resistance, and reduced cost. These materials can take advantage of different properties of their constituents, microstructure, and interaction between constituents in order to improve the mechanical behavior of parts made from them. The mechanics of fiber-reinforced composites are complex due to their anisotropic and heterogeneous characteristics. The evaluation of effective mechanical and thermal properties of composite materials is of paramount importance in engineering design and application. Generally, two approaches are considered in obtaining the global properties of composites: (a) macromechanical analysis and (b) micromechanical analysis. In macromechanical analysis the composite material is considered as a homogeneous orthotropic continuum. In micromechanical analysis the study of composite material is at the fiber and matrix level. Typically the unit cell technique combined with the known material properties of fiber and matrix is used to determine the overall behavior of the composite [1]. A number of methods have been developed to predict and to simulate the mechanical and thermal behavior of composites. Basic analytical approaches have been reported [2-4] to predict the composite materials properties, for example, strength, stiffness, and thermal conductivity. Prediction of boron and aluminium composite properties from a representative volume element (RVE) with square and hexagonal geometry has been reported [5]. Micromechanical 
analysis of unidirectional fiber-reinforced composites with square and hexagonal unit cells has been reported $[6,7]$ to evaluate the effective material properties.

Patnaik et al. [8] studied the micromechanical and thermal characteristics of glass-fiber-reinforced polymer composites. The experimental results were in good agreement with finite element model based on representative area element approach. Melro et al. [9] predict the inelastic deformation and fracture of randomly distributed unidirectional fiber-reinforced polymer composite materials with different RVEs. Several researchers made their significant contribution in studying thermal characteristics of fiber composites. Springer and Tsai [10] studied the composite thermal conductivities of unidirectional composites and expressions are obtained for predicting these conductivities in the directions along the filaments and normal to them. Islam and Pramila [11] predict the effective transverse thermal conductivity of fiber-reinforced composites by using finite element method. Square and circular cross section fibers were used for perfect bonding at fiber-matrix interface and with interfacial barrier by using four different sets of thermal boundary conditions. Al-Sulaiman et al. [12] predict the thermal conductivity of the constituents of fiber-reinforced composite laminates using three empirical formulas. Grove [13] computed transverse thermal conductivity in continuous unidirectional fiber composite materials using finite element and spatial statistical techniques for a range of fiber volume fractions up to 0.5. $\mathrm{Lu}$ [14] used boundary collocation scheme for calculation of transverse effective thermal conductivity of 2-dimensional periodic arrays of long circular and square cylinders with square array and long circular cylinders with hexagonal array for a complete range of fiber volume fractions.

Although a great deal of work has already been done on fiber-reinforced polymer composites with circular cross-section of fiber, square cross section of fiber with different RVE models using finite element analysis is hardly been reported. To this end, the objective of the present work is developing a three-dimensional micromechanical RVE with a square and hexagonal packing geometry with circular and square fiber cross sections. A numerical homogenization technique based on the finite element analysis was used to evaluate the elastic modulus and thermal conductivity of composite. The finite element results are compared with the analytical methods. The aim is to demonstrate applicability of homogenization technique by using finite element method to predict material characteristics in advance.

\section{Materials and Methods}

In this present investigation, unidirectional glass fiber as reinforcement phase and epoxy as matrix phase for the composite material were considered. The fiber and matrix materials are considered as isotropic and homogeneous. The properties of the constituent materials are as shown in Table 1. In a real unidirectional fiber-reinforced composite, the fibers are arranged randomly and it is difficult to model random fiber arrangement.

For this analysis, circular and square cross section fiber composite material is considered. The schematic diagram of
TABLE 1: Mechanical and thermal properties of the constituent materials $[8,9]$.

\begin{tabular}{lcc}
\hline Properties & Glass fiber & Epoxy matrix \\
\hline Density $\left(\mathrm{g} / \mathrm{cm}^{3}\right)$ & 2.5 & 1.15 \\
Young's modulus $(\mathrm{GPa})$ & 73 & 3.76 \\
Poisson's ratio & 0.2 & 0.39 \\
Shear modulus $(\mathrm{GPa})$ & 30.42 & 1.28 \\
Thermal conductivity $(\mathrm{W} / \mathrm{mk})$ & 1.3 & 0.363 \\
\hline
\end{tabular}

the unidirectional fiber composite where the fibers are arranged in the square and hexagonal array is shown in Figure 1 . By varying the volume fraction of fiber from 0.1 to 0.7 the elastic and thermal properties of composite material are determined.

2.1. Constitutive Equations for Fiber Composite Material. The most general form of the anisotropic constitutive equations for homogeneous and elastic composite materials is given by Hook's law as shown in (1) [15]. Consider

$$
\begin{aligned}
\left\{\begin{array}{l}
\sigma_{1} \\
\sigma_{2} \\
\sigma_{3} \\
\sigma_{4} \\
\sigma_{5} \\
\sigma_{6}
\end{array}\right\} & \equiv\left\{\begin{array}{l}
\sigma_{x x} \\
\sigma_{y y} \\
\sigma_{z z} \\
\tau_{y z} \\
\tau_{z x} \\
\tau_{x y}
\end{array}\right\} \\
& =\left[\begin{array}{llllll}
C_{11} & C_{12} & C_{13} & C_{14} & C_{15} & C_{16} \\
C_{12} & C_{22} & C_{23} & C_{24} & C_{25} & C_{26} \\
C_{13} & C_{23} & C_{33} & C_{34} & C_{35} & C_{36} \\
C_{14} & C_{24} & C_{34} & C_{44} & C_{45} & C_{46} \\
C_{15} & C_{25} & C_{35} & C_{45} & C_{55} & C_{56} \\
C_{16} & C_{26} & C_{36} & C_{46} & C_{56} & C_{66}
\end{array}\right]\left\{\begin{array}{l}
\varepsilon_{x x} \\
\varepsilon_{y y} \\
\varepsilon_{z z} \\
\gamma_{y z} \\
\gamma_{z x} \\
\gamma_{x y}
\end{array}\right\} \\
& \equiv\left\{\begin{array}{l}
\varepsilon_{1} \\
\varepsilon_{2} \\
\varepsilon_{3} \\
\varepsilon_{4} \\
\varepsilon_{5} \\
\varepsilon_{6}
\end{array}\right\},
\end{aligned}
$$

where $\sigma_{i j}$ and $\tau_{i j}$ are normal and shear components of stress, respectively, $\varepsilon_{i j}$ and $\gamma_{i j}$ are the normal and shear components of strain, respectively, and $C_{i j}$ is the symmetric stiffness matrix with 21 independent, elastic constants. According to their behaviour, composites may be characterized as generally anisotropic, monoclinic, orthotropic, and transversely isotropic. In present work, transversely isotropic characteristics have been considered for the fiber-reinforced composite. A transversely isotropic material is to be a material whose 


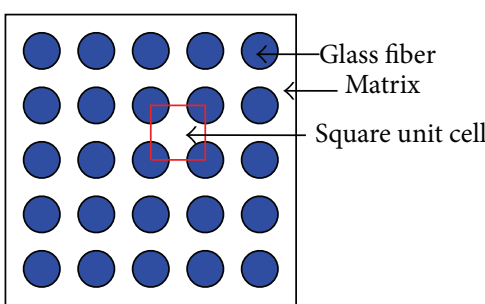

(a)

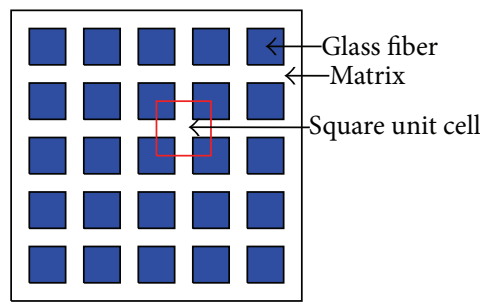

(c)

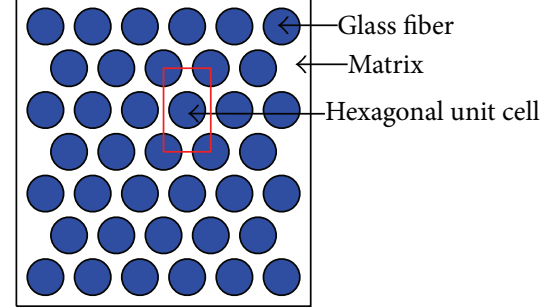

(b)

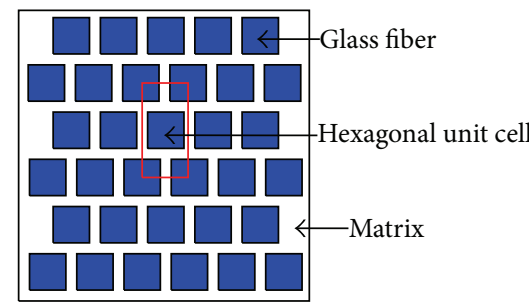

(d)

Figure 1: Arrangement of fibers in (a) square array with circular fibers, (b) hexagonal array with circular fibers, (c) square array with square fibers, and (d) hexagonal array with square fibers.

effective properties are isotropic in one of its planes and the stiffness tensor is represented in

$$
\begin{aligned}
\left\{\begin{array}{l}
\sigma_{1} \\
\sigma_{2} \\
\sigma_{3} \\
\sigma_{4} \\
\sigma_{5} \\
\sigma_{6}
\end{array}\right\} \\
= \\
=\left[\begin{array}{cccccc}
C_{11} & C_{12} & C_{12} & 0 & 0 & 0 \\
C_{12} & C_{22} & C_{23} & 0 & 0 & 0 \\
C_{12} & C_{23} & C_{22} & 0 & 0 & 0 \\
0 & 0 & 0 & \frac{1}{2}\left(C_{22}-C_{23}\right) & 0 & 0 \\
0 & 0 & 0 & 0 & C_{66} & 0 \\
0 & 0 & 0 & 0 & 0 & C_{66}
\end{array}\right]\left\{\begin{array}{l}
\varepsilon_{1} \\
\varepsilon_{2} \\
\varepsilon_{3} \\
\varepsilon_{4} \\
\varepsilon_{5} \\
\varepsilon_{6}
\end{array}\right\} .
\end{aligned}
$$

Once the components of the transversely isotropic stiffness tensor $C$ are known, the elastic properties of homogenized material can be computed by (3) [16]. Consider

$$
\begin{gathered}
E_{1}=C_{11}-\frac{2 C_{12}^{2}}{\left(C_{22}+C_{23}\right)}, \\
E_{2}=\frac{\left[C_{11}\left(C_{22}+C_{23}\right)-2 C_{12}^{2}\right]\left(C_{22}-C_{23}\right)}{\left(C_{11} C_{22}-C_{12}^{2}\right)}, \\
v_{12}=\frac{C_{12}}{\left(C_{22}+C_{23}\right)}, \\
G_{23}=\frac{1}{2}\left(C_{22}-C_{23}\right),
\end{gathered}
$$

where $E_{1}, E_{2}, v_{12}$, and $G_{23}$ are longitudinal modulus, transverse modulus in plane Poisson's ratio, and in plane shear modulus, respectively.

2.2. Generation of RVE. For simplicity reasons, most micromechanical models assume a periodic arrangement of fibers for which a RVE or unit cell can be isolated. The RVE has the same elastic constants and fiber volume fraction as the composite. The periodic fiber sequences commonly used are the square array and the hexagonal array. For a square packing RVE as shown in Figures 2(a) and 2(c) the maximum theoretically achievable fiber volume fraction is $78.54 \%$. For square RVE the diameter of fiber is calculated by

$$
V_{f}=\frac{a_{1}(\pi / 4) d_{f}^{2}}{a_{1} a_{2} a_{3}},
$$

where $V_{f}$ is volume fraction of fiber; $a_{1}, a_{2}$, and $a_{3}$ are the length of square RVE; and $d_{f}$ is the diameter of fiber. For the hexagonal packing RVE as shown in Figures 2(b) and 2(d) the maximum theoretically achievable fiber volume fraction is $90.69 \%$. Obviously, with a hexagonal packing geometry a composite can be made more compact than with a square packing geometry. For hexagonal RVE the diameter of fiber is calculated by

$$
V_{f}=\frac{2 a_{1}(\pi / 4) d_{f}^{2}}{a_{1} a_{2} a_{3}},
$$

where $a_{3}=a_{2} \tan \left(60^{\circ}\right)$ and $a_{2}=4 a_{1}$.

\section{Finite Element Modeling}

In order to evaluate the effective properties of composite, the finite element software package ANSYS is used. The program 

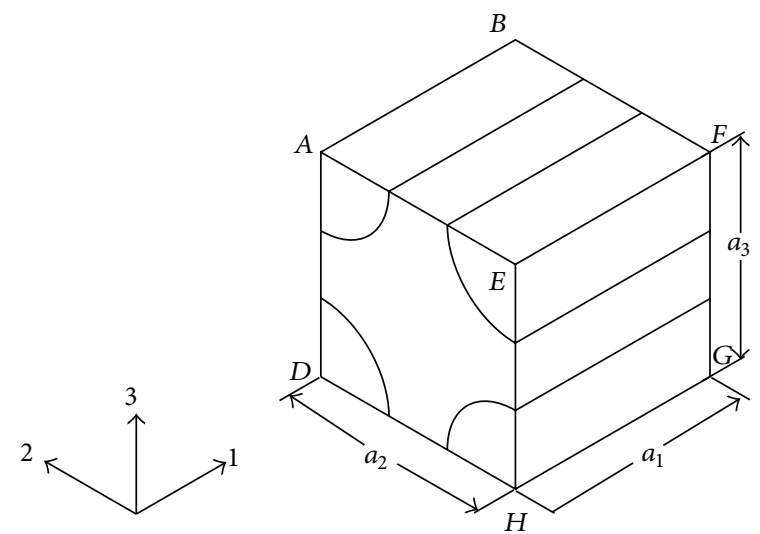

(a)

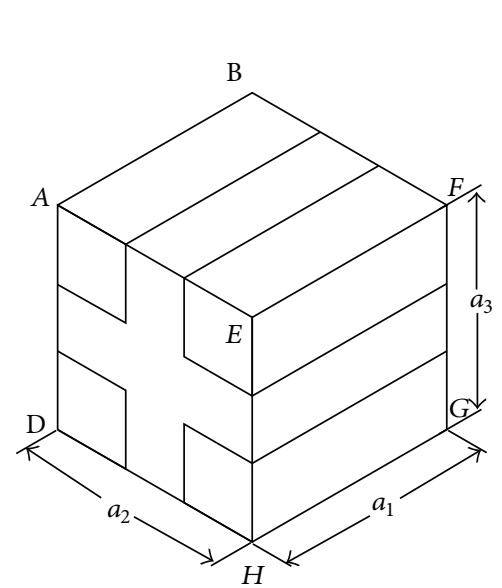

(c)

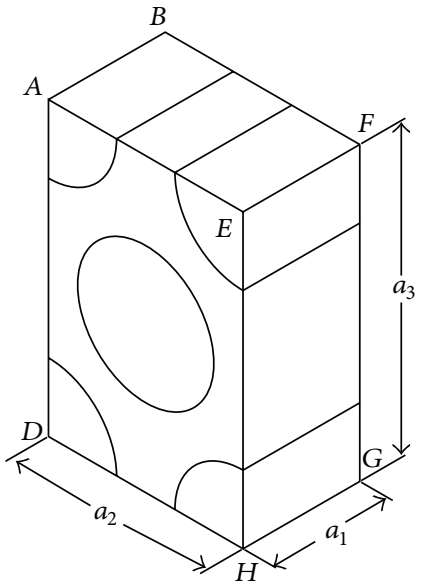

(b)

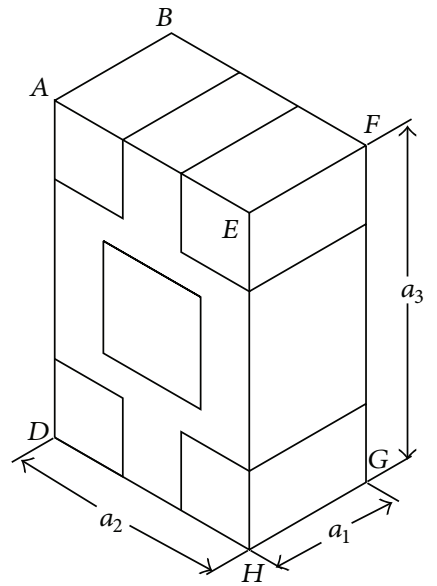

(d)

FIGURE 2: RVE (a) square RVE with circular fiber, (b) hexagonal RVE with circular fiber, (c) square RVE with square fiber, and (d) hexagonal RVE with square fiber.

is written in APDL (ANSYS Programming Design Language), which is delivered by the software and it makes the handling much more comfortable. For simplification, there are many assumptions considered for the present analysis such as fibers which are arranged in a particular pattern (square and hexagonal) in a matrix. The composite is free of voids and other irregularities, all fibers are uniformly distributed in the matrix and perfectly aligned, and the interface between the fiber and matrix is perfectly debonded. In the study of the micromechanics of fiber-reinforced materials, it is convenient to use an orthogonal coordinate system that has one axis aligned with the fiber direction. The axis 1 is aligned with the fiber direction, the axis 2 is in the plane of the RVE and is perpendicular to the fibers, and the axis 3 is perpendicular to the plane of the RVE and is also perpendicular to the fibers as shown in Figure 2. Dimensions considered for the analysis are $a_{1}=1.0 \times 10^{-5} \mathrm{~m}, a_{2}=1.0 \times 10^{-5} \mathrm{~m}$, and $a_{3}=1.0 \times 10^{-5} \mathrm{~m}$ for square RVE. For hexagonal RVE $a_{1}=1.0 \times 10^{-5} \mathrm{~m}, a_{2}$ and $a_{3}$ are calculated by using (5). The radius of fibers corresponds to volume fractions ranging from 0.1 to 0.7 . Three-dimensional structural solid element SOLID186 is used to determine elastic properties and is defined by 20 nodes having three degrees of freedom at each node. They are translations in the nodal 1, 2, and 3 directions. For thermal conductivity a threedimensional quadratic brick element SOLID90 is used for discretization of the constituents and is defined by 20 nodes with a single degree of freedom (temperature) at each node. The meshed model of square and hexagonal RVE at 0.4 of fiber volume fraction is shown in Figure 3.

3.1. Boundary Conditions for Evaluation of Elastic Properties. Composite materials can be represented as a periodic array of the RVEs. Therefore, the periodic boundary conditions must be applied to the RVE models. This implies that each RVE in the composite has the same deformation mode and there is no separation or overlap between the neighboring RVEs after deformation $[17,18]$. The resumed boundary conditions applied are given in Table 2 . Note that $U, V$, and $W$ are the displacements along 1,2, and 3 directions, respectively, applied on the AEDH, BFCG, ABCD, EFGH, DHGC, and AEFB faces as shown in Figure 2. After applying boundary conditions and the displacement constant, the corresponding 
TABLE 2: Boundary conditions along the 1,2, and 3 directions of the RVE.

\begin{tabular}{|c|c|c|c|c|c|c|c|}
\hline \multirow{2}{*}{ Load } & \multirow{2}{*}{ Constraint } & \multicolumn{2}{|c|}{ 1-direction faces } & \multicolumn{2}{|c|}{ 2-direction faces } & \multicolumn{2}{|c|}{ 3-direction faces } \\
\hline & & AEDH & BFCG & $\mathrm{ABCD}$ & EFGH & DHGC & AEFB \\
\hline \multirow{3}{*}{ Load 11} & $\mathrm{U}$ & 0 & $a_{1}$ & & & & \\
\hline & $\mathrm{V}$ & & & 0 & 0 & & \\
\hline & $\mathrm{W}$ & & & & & 0 & 0 \\
\hline \multirow{3}{*}{ Load 22} & $\mathrm{U}$ & 0 & 0 & & & & \\
\hline & V & & & 0 & $a_{2}$ & & \\
\hline & $\mathrm{W}$ & & & & & 0 & 0 \\
\hline \multirow{3}{*}{ Load 33} & $\mathrm{U}$ & 0 & 0 & & & & \\
\hline & V & & & 0 & 0 & & \\
\hline & $\mathrm{W}$ & & & & & 0 & $a_{3}$ \\
\hline
\end{tabular}

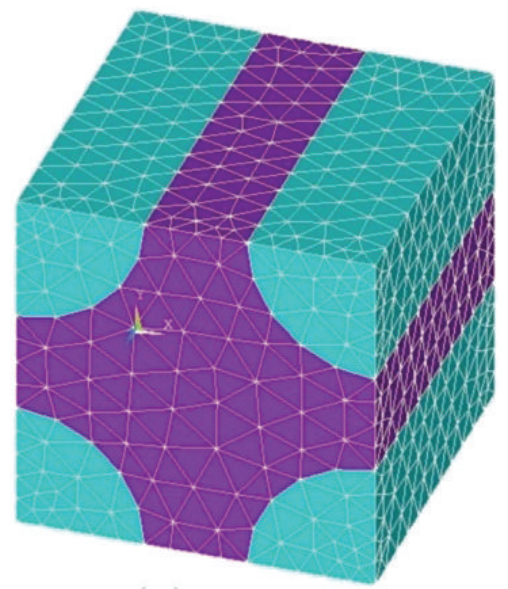

(a)

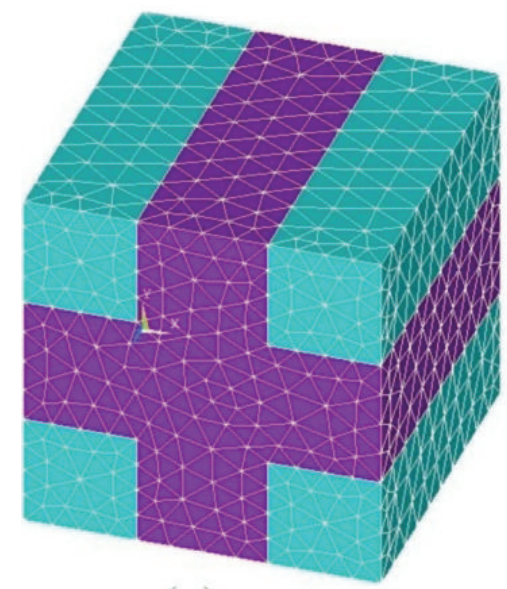

(c)

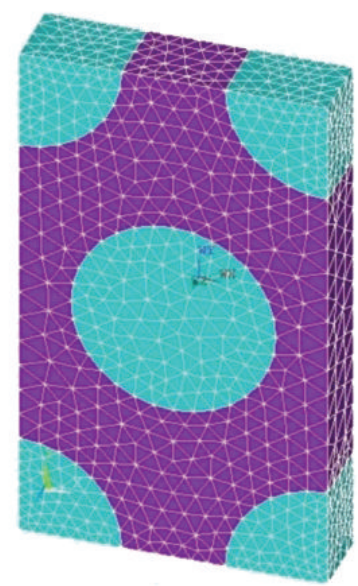

(b)

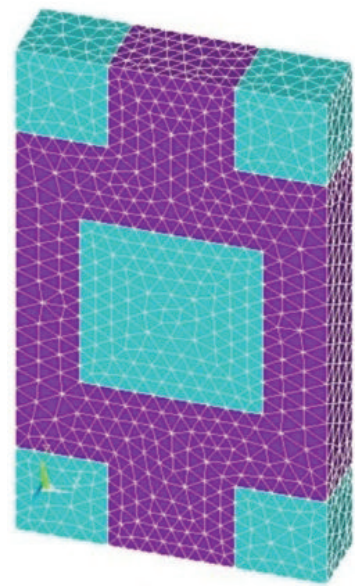

(d)

FIGURE 3: Meshed model of (a) square RVE with circular fiber, (b) hexagonal RVE with circular fiber, (c) square RVE with square fiber, and (d) hexagonal RVE with square fiber. 


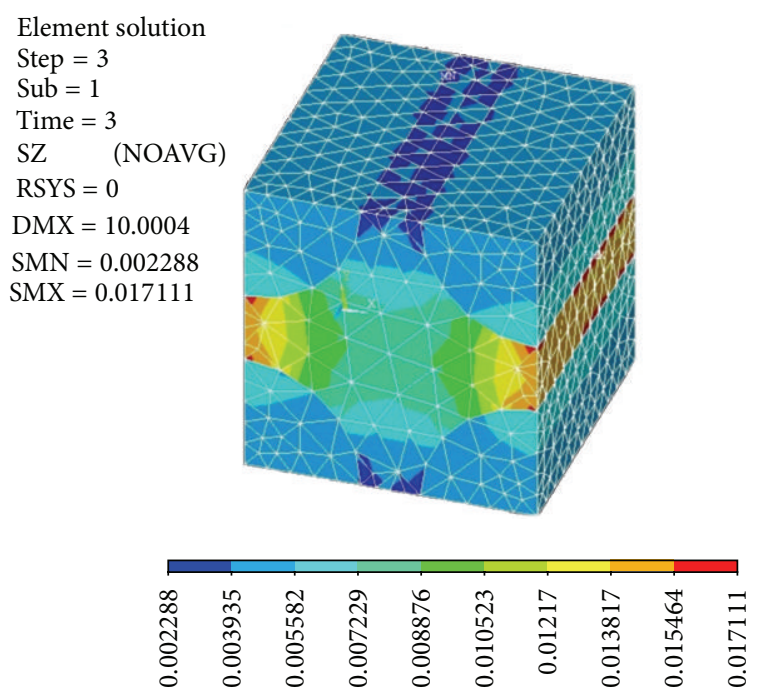

(a)

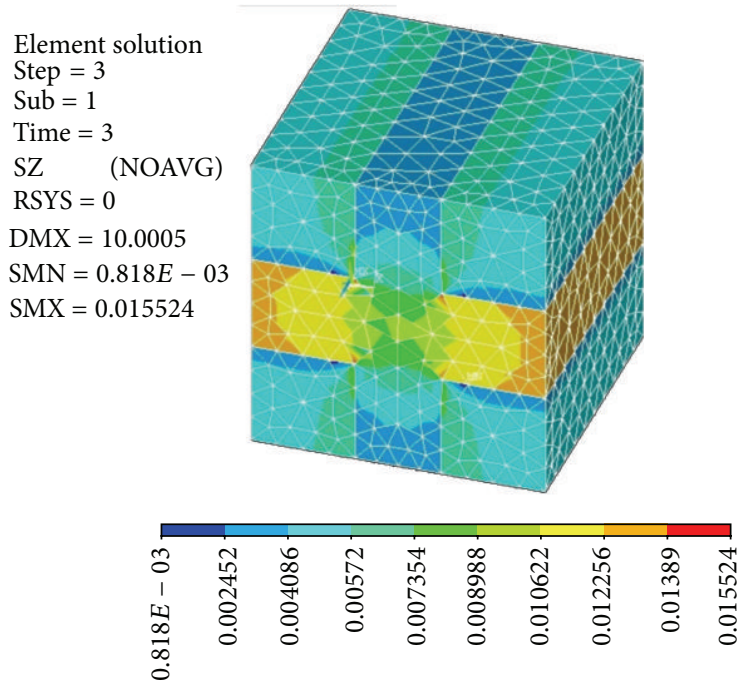

(c)
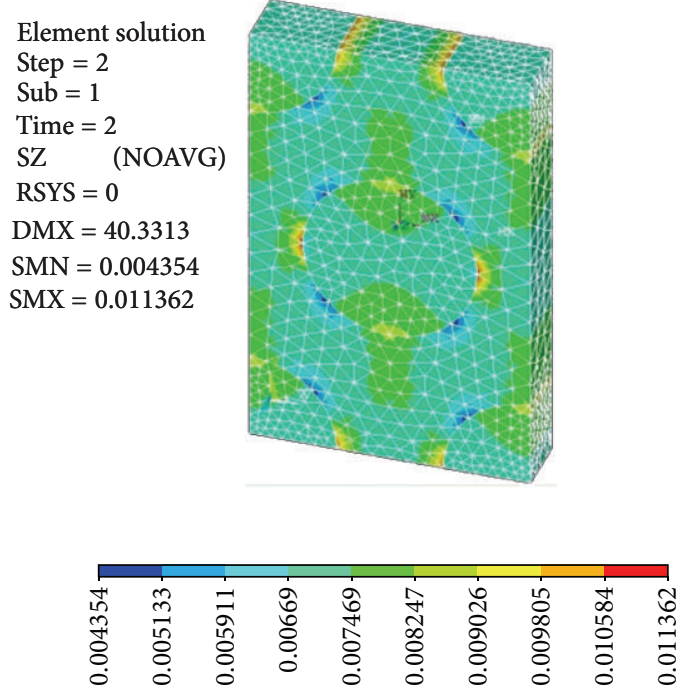

(b)

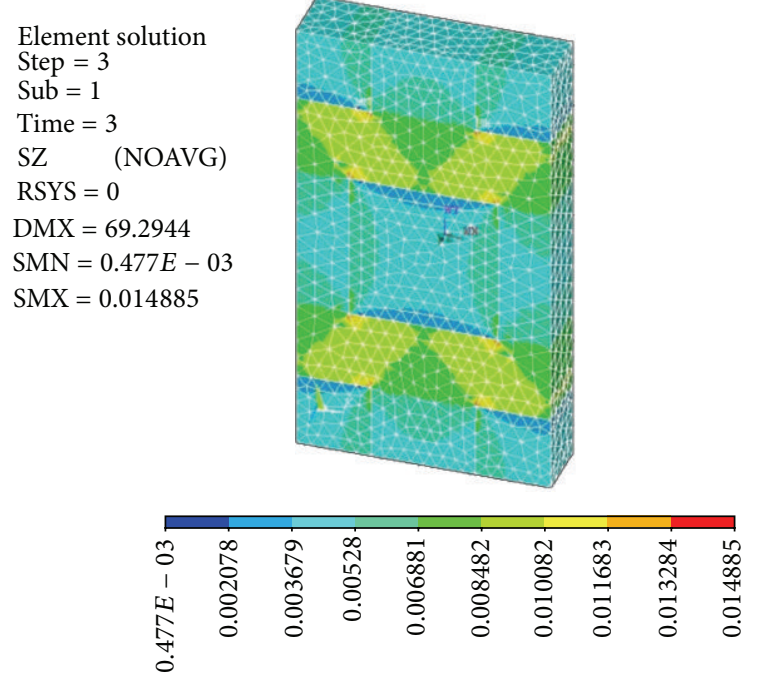

(d)

FIGURE 4: Counter of stress in (a) square RVE with circular fiber, (b) hexagonal RVE with circular fiber, (c) square RVE with square fiber, and (d) hexagonal RVE with square fiber.

engineering constants are calculated as follows in terms of corresponding stresses and strains shown in (6):

$$
\begin{aligned}
\overline{\sigma_{i j}} & =\frac{1}{V} \int_{V} \sigma_{i j} d V, \\
\overline{\varepsilon_{i j}} & =\frac{1}{V} \int_{V} \varepsilon_{i j} d V,
\end{aligned}
$$

where $\bar{\sigma}$ and $\bar{\varepsilon}$ are the average stresses and average strains and $V$ is the volume of the RVE. The elastic properties can be calculated by using the constitutive equations of the material properties as the ratio of corresponding average stresses and average strains as shown in (3). Figures 4 and 5 show the counter of stress and strain in square and hexagonal RVE at 0.4 of volume fraction.
3.2. Boundary Conditions for Evaluation of Thermal Conductivity. The steady state heat transfer simulations are performed by using finite element analysis to predict thermal conductivity of composite along the longitudinal and transverse direction. The thermal boundary conditions considered in the present analysis are shown in Figure 2. One wall (BFGC) is kept isothermal at elevated temperature, while the corresponding wall (AEHD) is subjected 100 Kelvin to maintain temperature difference for the calculation of longitudinal thermal conductivity. All other surfaces are subjected to insulation boundary conditions. One wall $(A B C D)$ is kept isothermal at elevated temperature, while the corresponding wall (EFGH) is subjected 100 Kelvin to maintain temperature difference for the calculation of transverse thermal conductivity. All other surfaces are subjected to insulation boundary 


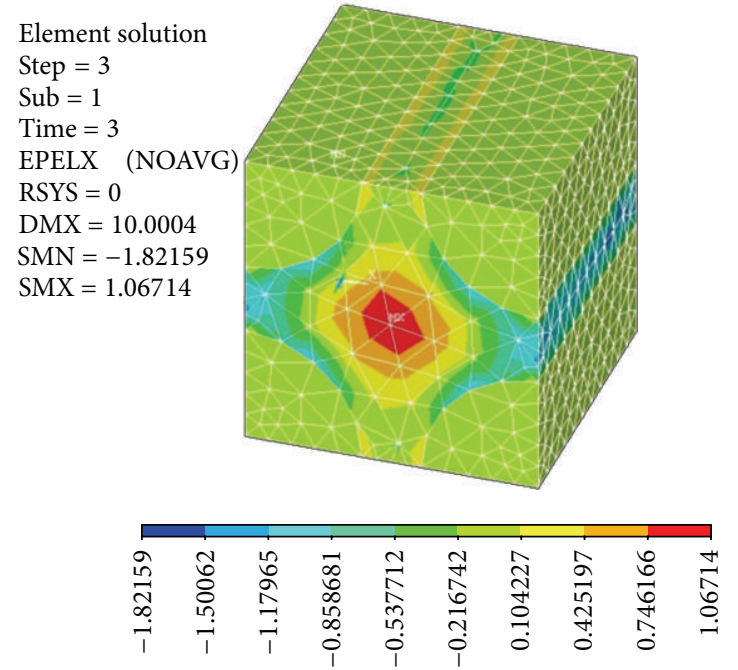

(a)

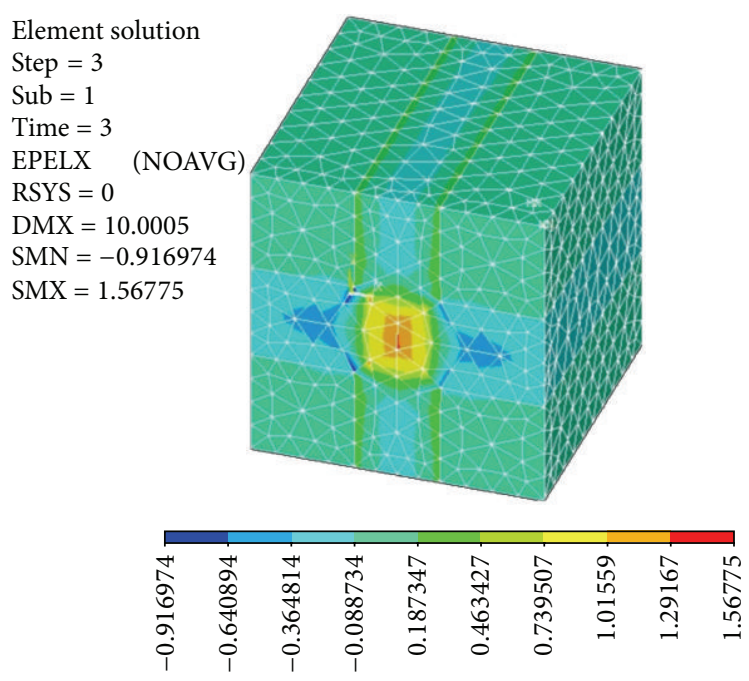

(c)

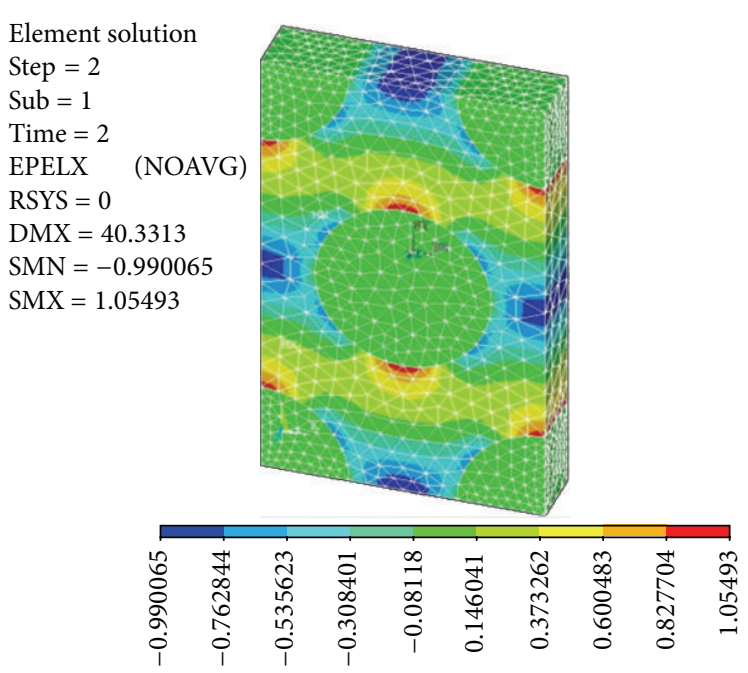

(b)

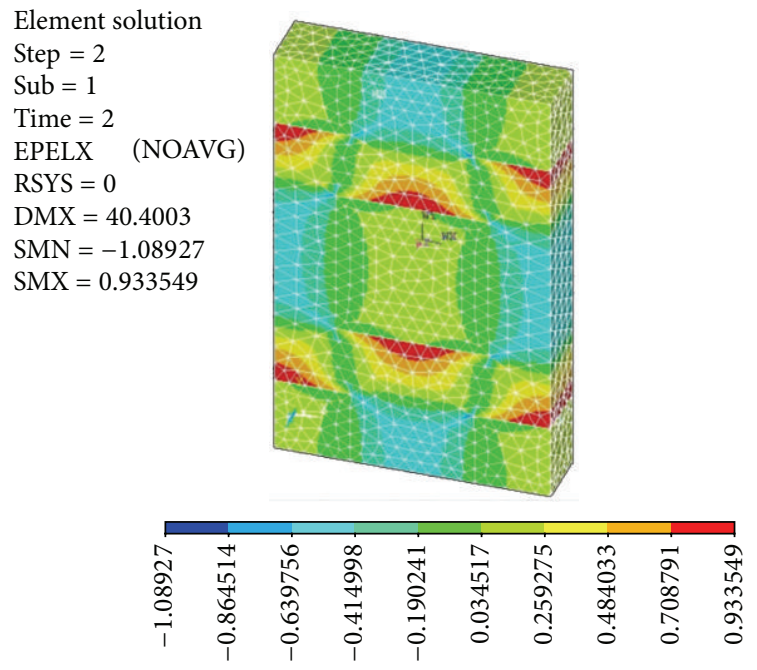

(d)

FIgURE 5: Counter of strain in (a) square RVE with circular fiber, (b) hexagonal RVE with circular fiber, (c) square RVE with square fiber, and (d) hexagonal RVE with square fiber.

conditions. Using these temperature gradients the heat flux was obtained from ANSYS software.

The effective thermal conductivity is established from the fundamental heat conduction law, found by Fourier's, which states that the heat flux is proportional to the temperature gradient [19]:

$$
q=-K \frac{d T}{d x}
$$

where $d T / d x$ is temperature gradient between two isothermal surfaces, $q$ is the heat flux $\mathrm{W} / \mathrm{m}^{2}$, and $k$ is the thermal conductivity. The temperature distribution in square and hexagonal RVE along longitudinal and transverse direction at 0.4 of volume fraction of fiber is shown in Figures 6 and 7.

\section{Analytical Methods}

In order to validate the finite element results, three wellexisting analytical methods such as rule of mixture, semiempirical model, and periodic microstructure models have been used for the current study.

4.1. Rule of Mixture Model. The well-known models that have been proposed and used to evaluate the properties of unidirectional composites are the Voigt and Reuss models which are also known as the rule of mixture model and the inverse rule of mixture model. The rule of mixture is the mathematical expressions which give the property of the composite in terms of the properties, quantity, and arrangement of its constituents. The longitudinal property of 


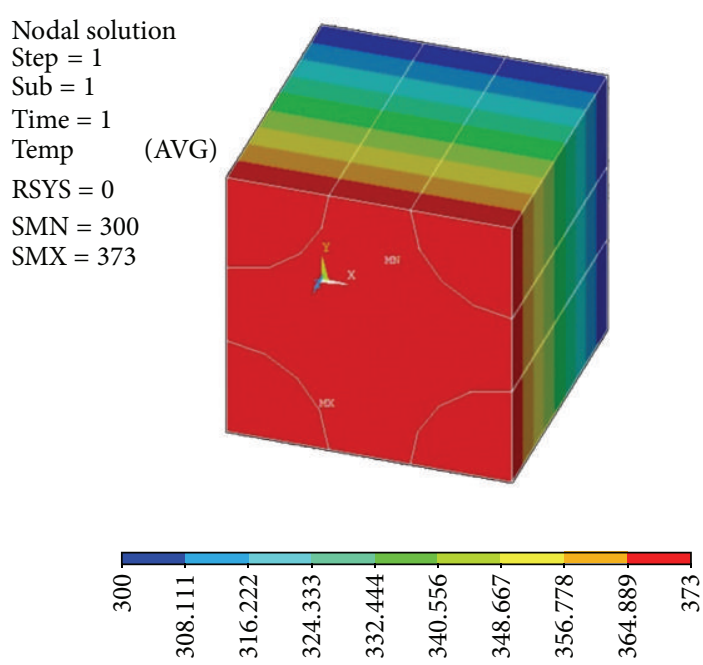

(a)

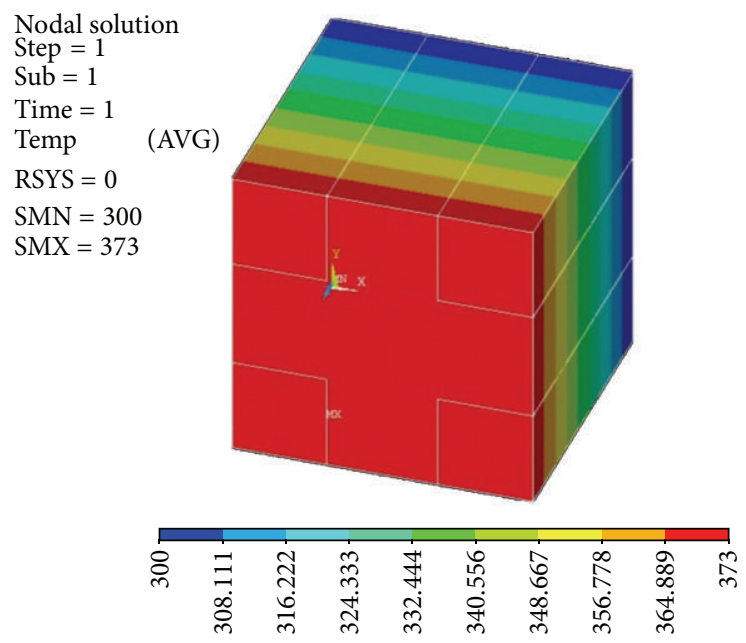

(c)
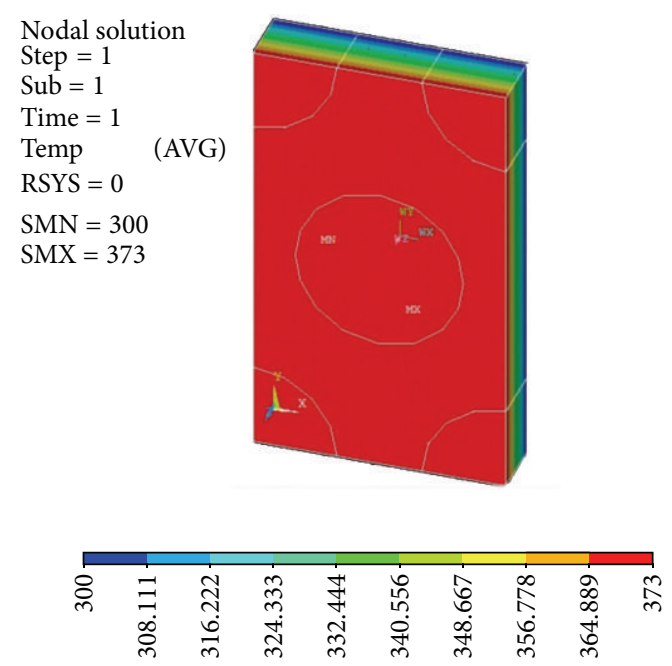

(b)
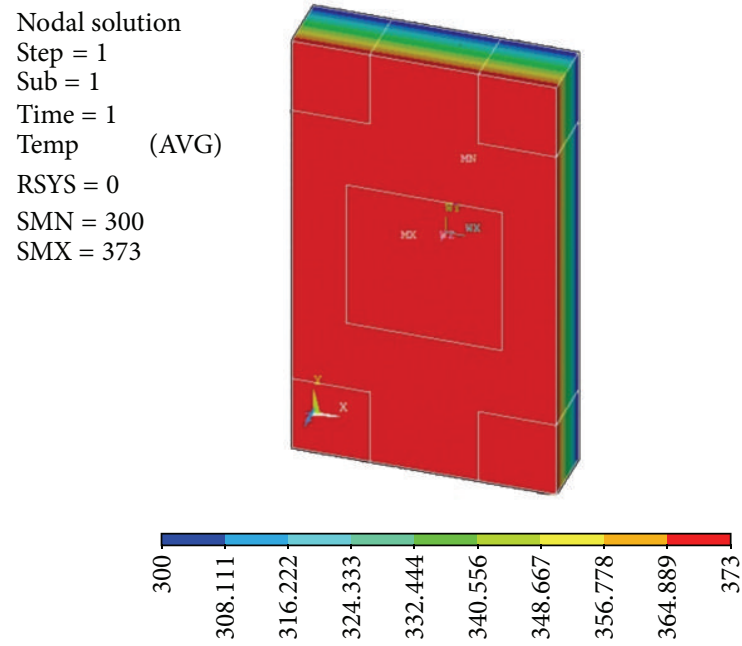

(d)

FIGURE 6: Longitudinal temperature distribution in (a) square RVE with circular fiber, (b) hexagonal RVE with circular fiber, (c) square RVE with square fiber, and (d) hexagonal RVE with square fiber.

the composite is calculated by using rule of mixture as shown in

$$
\phi_{1}=\phi_{f} V_{f}+\phi_{m} V_{m}
$$

where $\phi_{1}$ is the property of composite in longitudinal direction. $\phi_{f}$ and $\phi_{m}$ are the material properties of fiber and epoxy matrix. $V_{f}$ and $V_{m}$ are the volume fractions of fiber and epoxy matrix. The transverse modulus of composite is calculated by using rule of mixture as shown in

$$
\frac{1}{\phi_{2}}=\frac{V_{f}}{\phi_{f}}+\frac{V_{m}}{\phi_{m}}
$$

where $\phi_{2}$ is the property of composite in transverse direction.

4.2. Halpin-Tsai Model. The most useful semiempirical models are those by Halpin and Tsai. Halpin and Tsai developed their models as simple equations by curve fitting to results that are based on elasticity. The material properties calculated in longitudinal direction by using Halpin-Tsai model are the same as those in rule of mixtures. For the transverse direction, the material property of composite is calculated by

$$
\frac{\phi_{2}}{\phi_{m}}=\frac{1+\zeta \eta V_{f}}{1-\eta V_{f}}
$$

where $\eta=\left(\left(\phi_{f} / \phi_{m}\right)-1\right) /\left(\left(\phi_{f} / \phi_{m}\right)+\zeta\right)$.

Halpin and Tsai found that the value $\xi=2$ gave an excellent fit to the finite difference elasticity solution of Adams and Doner [20] for the transverse modulus of a square array of circular fibers.

4.3. Periodic Microstructure. If the composite has periodic microstructure, then Fourier series can be used to estimate 


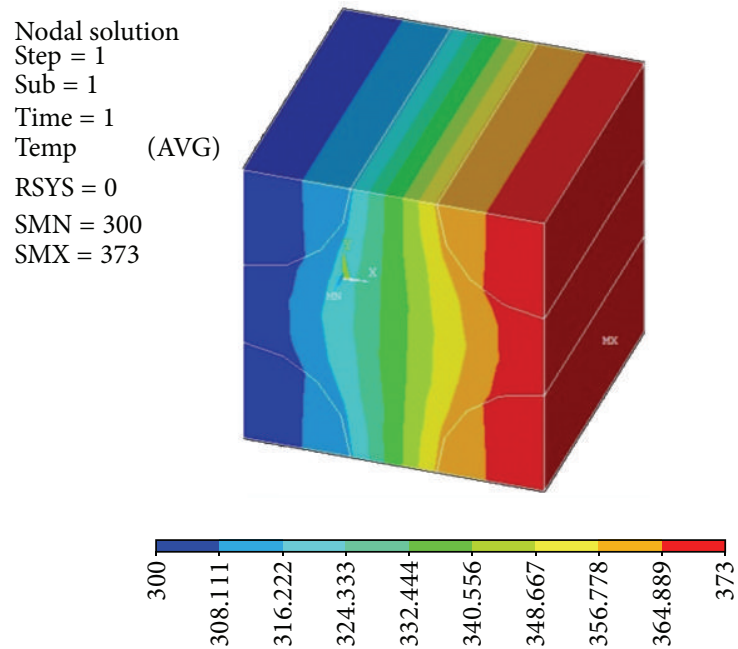

(a)

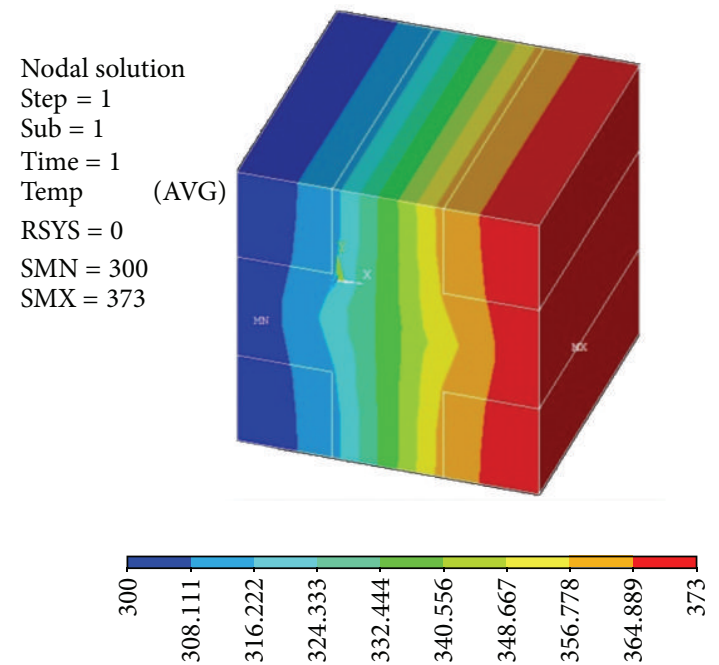

(c)
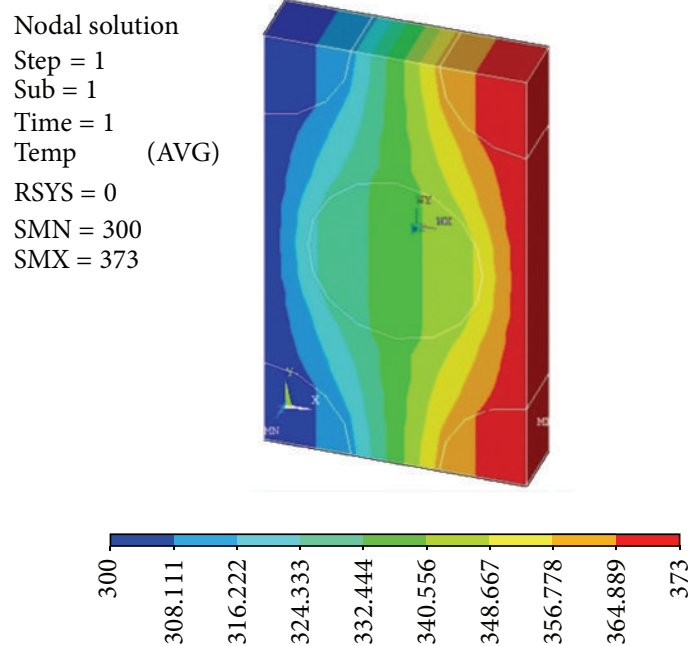

(b)

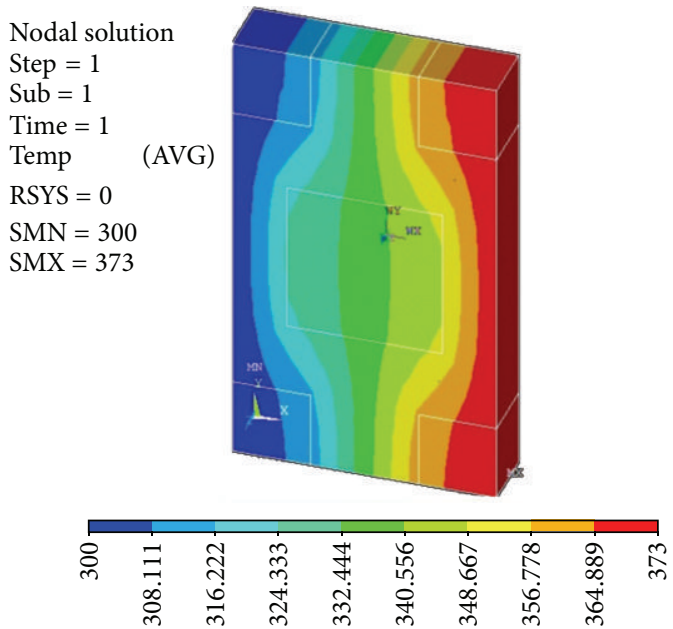

(d)

FIgURE 7: Transverse temperature distribution in (a) square RVE with circular fiber, (b) hexagonal RVE with circular fiber, (c) square RVE with square fiber, and (d) hexagonal RVE with square fiber.

all the components of the stiffness tensor of the composite. Explicit formulas for a composite reinforced by long circular cylindrical fibers were discussed in [21].

4.4. Thermal Conductivity Models. Thermal conductivity obtained by finite element analysis, comparing with three well-existing analytical methods such as rule of mixture, the Chawla model, and the Hashin model [22], has been used for the current study.

\section{Results and Discussion}

5.1. Effect of Volume Fraction on Elastic Properties. The longitudinal modulus is the response of composite during the application of load parallel to the fiber direction. It can be defined as the ratio of longitudinal stress to the longitudinal strain. Figure 8 shows the effect of fiber content on the longitudinal modulus of composites using rule of mixtures, Halpin-Tsai model, periodic microstructure, and finite element analysis with square and hexagonal RVE with circular and square fiber geometry. It can be observed from the figure that the longitudinal modulus increases with the increase in volume fraction of fiber and there is a good agreement between finite element results and analytical methods. This is because the stiffness of the composite increases with increase in volume fraction of fiber.

The transverse modulus is the response of composite during the application of load perpendicular to the fiber direction. It can be defined as the ratio of transverse stress to the transverse strain. The effect of fiber volume fraction on transverse modulus of composites using finite element analysis and three analytical methods is graphically shown in Figure 9. As expected, it is clear from the figure that 


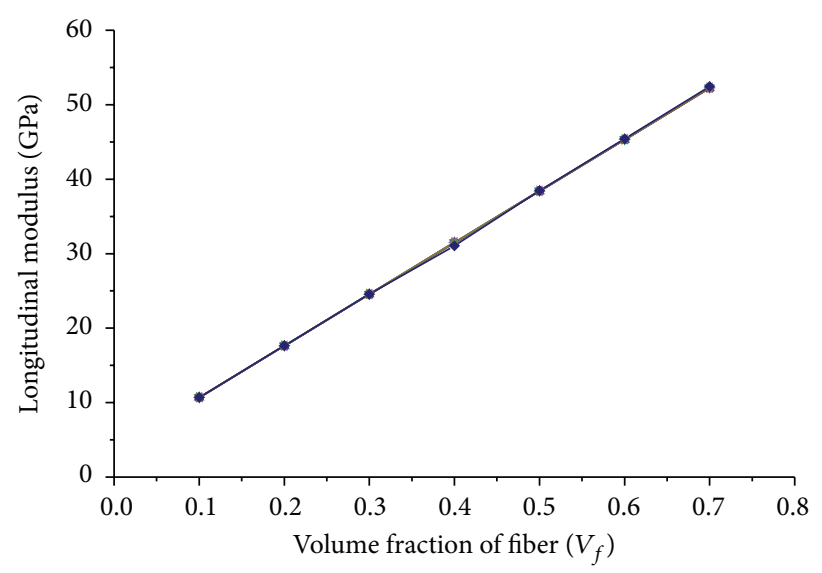

$$
\begin{array}{llll}
-\bullet- & \text { Rule of mixture } & -\triangleleft- & \text { FEA circular-hexagonal RVE } \\
-\bullet- & \text { Halpin-Tsai } & -\bullet- & \text { FEA square-square RVE } \\
-\bullet- & \text { Periodic microstructure } & -\bullet- & \text { FEA square-hexagonal RVE } \\
-\checkmark- & \text { FEA circular-square RVE } & &
\end{array}
$$

FIGURE 8: Longitudinal modulus validation with different volume fraction of fiber.

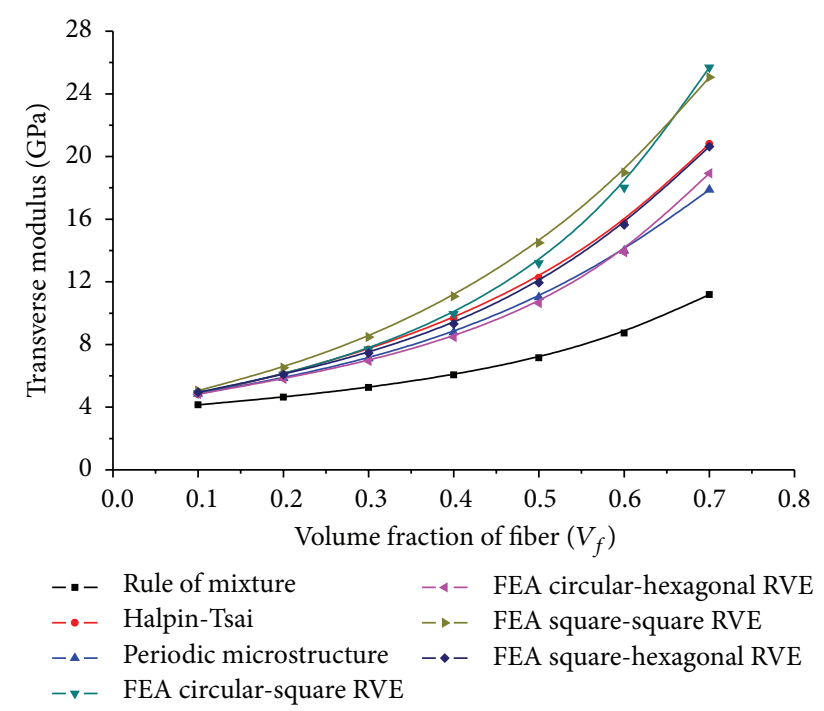

FIGURE 9: Transverse modulus validation with different volume fraction of fiber.

the transverse modulus increases with increase in fiber volume fraction. The transverse modulus evaluated by finite element analysis with hexagonal RVE is more close to the Halpin-Tsai model and periodic microstructure as compared to the results obtained from rule of mixture and finite element analysis with square RVE.

Figure 10 shows the effect of fiber volume fraction on the in-plane Poisson's ratio of composite. It is evident from the figure that the major Poisson's ratio decreases with increase in the volume fraction of fiber due to increase in material resistance. The finite element results are in good agreement with analytical methods.

In-plane shear modulus of composite is the ratio of shear stress to the shear strain in longitudinal direction. Figure 11

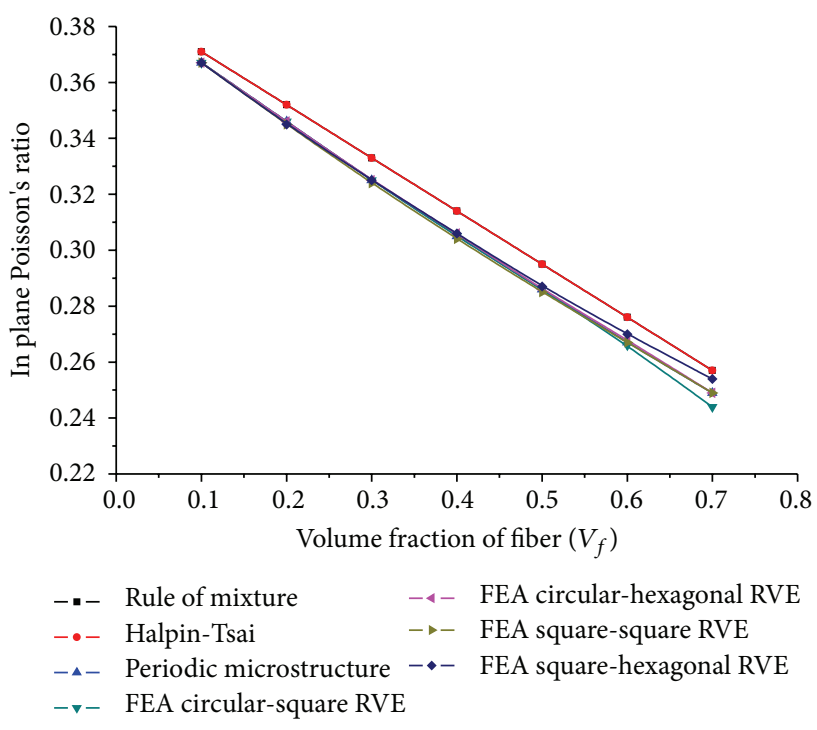

FIGURe 10: In-plane Poisson's ratio validation with different volume fraction of fiber.

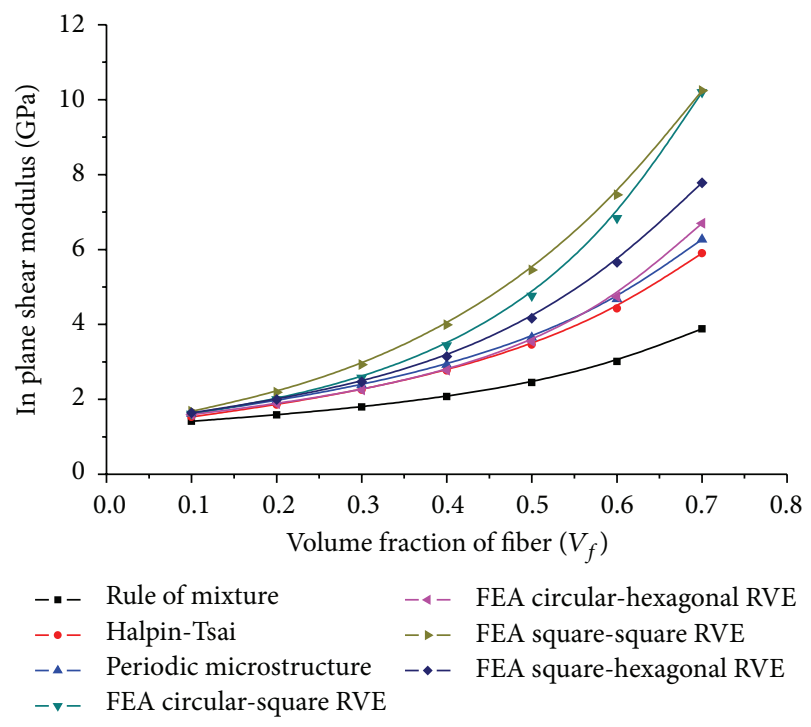

FIGURE 11: In-plane shear modulus validation with different volume fraction of fiber.

shows the effect of fiber volume fraction on the in-plane shear modulus of composite. It is clear from the figure that the shear modulus increases with increases in fiber volume fraction. Also, it can be observed that there is a good agreement between results obtained from finite element analysis and hexagonal RVE with Halpin-Tsai model and periodic microstructure as compared to rule of mixture and finite element analysis with square RVE.

5.2. Effect of Volume Fraction on Thermal Conductivity. Longitudinal thermal conductivity of composite is the property of a material to conduct heat in parallel to the direction of the fibers. Figure 12 shows the effect of fiber content on the longitudinal thermal conductivity using rule of mixture, 


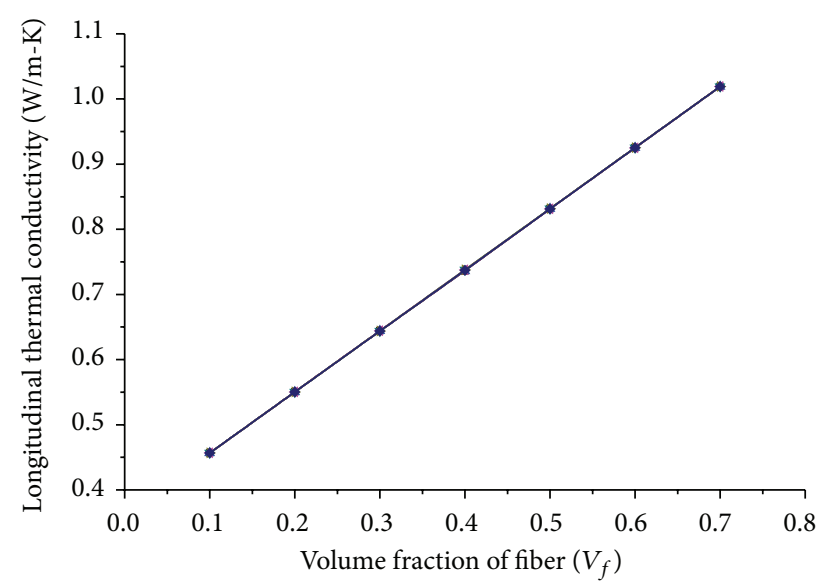

$\begin{array}{llll}-\bullet- & \text { Rule of mixture } & -\triangleleft- & \text { FEA circular-hexagonal RVE } \\ -\bullet- & \text { Chawla model } & -\bullet- & \text { FEA square-square RVE } \\ -\triangleleft- & \text { Hashin model } & -\bullet- & \text { FEA square-hexagonal RVE } \\ -\checkmark- & \text { FEA circular-square RVE } & & \end{array}$

FIGURE 12: Longitudinal thermal conductivity validation with different volume fraction of fiber.

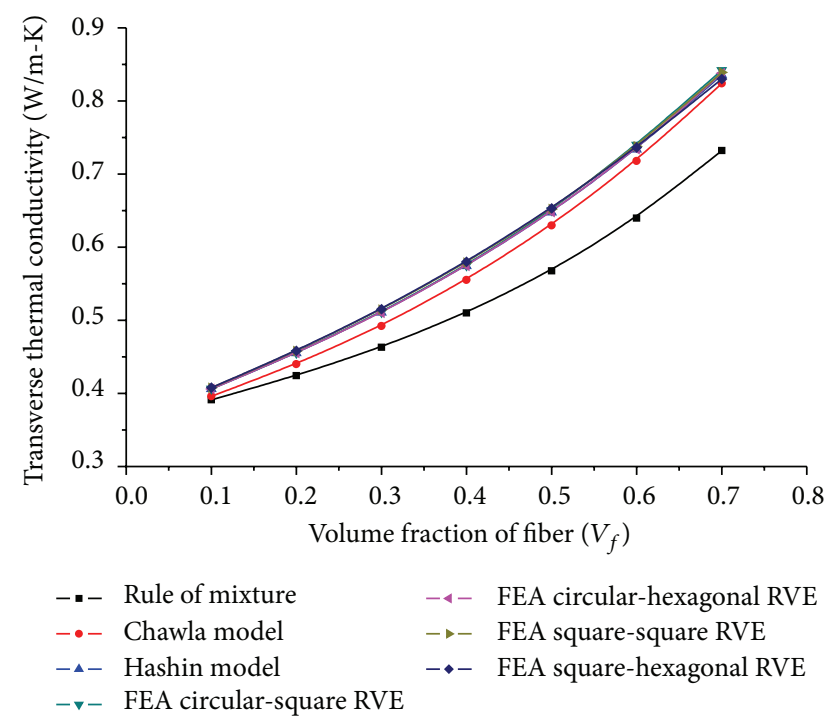

FIGURE 13: Transverse thermal conductivity validation with different volume fraction of fiber.

the Chawla model, the Hashin model, and finite element analysis. Finite element results match well the analytical methods and increases in linear manner with the increase in volume fraction since the fiber thermal conductivity dominates the matrix thermal conductivity.

Transverse thermal conductivity of composite is the property of a material to conduct heat, in the direction perpendicular to the fibers. Figure 13 shows the effect of fiber content on the transverse thermal conductivity using analytical methods and finite element analysis.

It is clear from the figure that the transverse thermal conductivity increases with increases in fiber volume fraction. The transverse thermal conductivity evaluated by finite element analysis with hexagonal RVE is more close to the Hashin model as compared to the results obtained from rule of mixture and the Chawla model.

\section{Conclusions}

In this work, the micromechanical approach has been studied to evaluate the elastic and thermal properties of unidirectional fiber-reinforced polymer composites with different volume fractions of fiber up to 0.7. The material properties obtained by finite element techniques were compared with different analytical methods. The following conclusions can be drawn.

(1) The finite element model based on three-dimensional RVE with a square and hexagonal packing geometry was successfully implemented by using finite element code ANSYS to calculate elastic and thermal properties.

(2) It has been observed that longitudinal modulus and in-plane Poisson's ratio predicted by the finite element analysis agree well with all the existing analytical predictions. Transverse modulus and in-plane shear modulus predicted by the finite element analysis with hexagonal RVE is more close to the periodic microstructure model as compared to finite element analysis with square RVE and other analytical methods.

(3) It has been observed that longitudinal thermal conductivity predicted by the finite element analysis agrees well with all analytical methods. Transverse thermal conductivity predicted by the finite element analysis with hexagonal array is more close to the Hashin model as compared to rule of mixture and Chawla model.

(4) In finite element analysis the elastic properties and thermal conductivity of fiber-reinforced composites are affected by a number of parameters such as cross section fiber, fiber geometry of RVE, and volume fraction of the fibers.

\section{Conflict of Interests}

The authors declare that there is no conflict of interests regarding the publication of this paper.

\section{References}

[1] J. Aboudi, "Micromechanical analysis of composites by the method of cells," Applied Mechanics Reviews, vol. 42, no. 7, pp. 193-221, 1989.

[2] Z. Hashin and B. W. Rosen, "The elastic moduli of fiber-reinforced materials," Journal Applied Mechanics, vol. 31, no. 2, pp. 223-232, 1964.

[3] Z. Hashin, "Analysis of properties of fiber composites with anisotropic constituents," Journal of Applied Mechanics, vol. 46, no. 3, pp. 543-550, 1979.

[4] Z. Hashin, "Analysis of composite materials-a survey," Journal Applied Mechanics, vol. 50, no. 3, pp. 481-505, 1983. 
[5] C. T. Sun and R. S. Vaidya, "Prediction of composite properties from a representative volume element," Composites Science and Technology, vol. 56, no. 2, pp. 171-179, 1996.

[6] S. Li, "General unit cells for micromechanical analyses of unidirectional composites," Composites: Part A: Applied Science and Manufacturing, vol. 32, no. 6, pp. 815-826, 2001.

[7] S. Li, "On the unit cell for micromechanical analysis of fibrereinforced composites," Proceedings of the Royal society A, vol. 455, no. 1983, pp. 815-838, 1999.

[8] A. Patnaik, P. Kumar, S. Biswas, and M. Kumar, "Investigations on micro-mechanical and thermal characteristics of glass fiber reinforced epoxy based binary composite structure using finite element method," Computational Materials Science, vol. 62, pp. 142-151, 2012.

[9] A. R. Melro, P. P. Camanho, F. M. Andrade Pires, and S. T. Pinho, "Micromechanical analysis of polymer composites reinforced by unidirectional fibres: part II-Micromechanical analyses," International Journal of Solids and Structures, vol. 50, no. 11-12, pp. 1906-1915, 2013.

[10] G. S. Springer and S. W. Tsai, “Thermal conductivities of unidirectional materials," Journal of Composite Materials, vol. 1, no. 2, pp. 166-173, 1967.

[11] M. R. Islam and A. Pramila, "Thermal conductivity of fiber reinforced composites by the FEM," Journal of Composite Materials, vol. 33, no. 18, pp. 1699-1715, 1999.

[12] F. A. Al-Sulaiman, E. M. A. Mokheimer, and Y. N. Al-Nassar, "Prediction of the thermal conductivity of the constituents of fiber reinforced composite laminates," Heat and Mass Transfer, vol. 42, no. 5, pp. 370-377, 2006.

[13] S. M. Grove, "A model of transverse thermal conductivity in unidirectional fibre-reinforced composites," Composites Science and Technology, vol. 38, no. 3, pp. 199-209, 1990.

[14] S.-Y. Lu, "The effective thermal conductivities of composites with 2-D arrays of circular and square cylinders," Journal of Composite Materials, vol. 29, no. 4, pp. 483-506, 1995.

[15] C. T. Herakovich, Mechanics of Fibrous Composites, John Wiley \& Sons, New York, NY, USA, 1998.

[16] E. J. Barbero, Finite Element Analysis of Composite Materials, CRC Press, Boca Raton, Fla, USA, 2011.

[17] M. Würkner, H. Berger, and U. Gabbert, "On numerical evaluation of effective material properties for composite structures with rhombic fiber arrangements," International Journal of Engineering Science, vol. 49, no. 4, pp. 322-332, 2011.

[18] S. Kari, H. Berger, R. Rodriguez-Ramos, and U. Gabbert, "Computational evaluation of effective material properties of composites reinforced by randomly distributed spherical particles," Composite Structures, vol. 77, no. 2, pp. 223-231, 2007.

[19] K. K. Chawla, Composite Materials: Science and Engineering, Springer, New York, NY, USA, 1987.

[20] D. F. Adams and D. R. Doner, "Transverse normal loading of a unidirectional composite," Journal of Composite Materials, vol. 1, no. 2, pp. 152-164, 1967.

[21] R. Luciano and E. J. Barbero, "Formulas for the stiffness of composites with periodic microstructure," International Journal of Solids and Structures, vol. 31, no. 21, pp. 2933-2944, 1994.

[22] R. C. Wetherhold and J. Wang, "Difficulties in the theories for predicting transverse thermal conductivity of continuous fiber composites," Journal of Composite Materials, vol. 28, no. 15, pp. 1491-1498, 1994. 

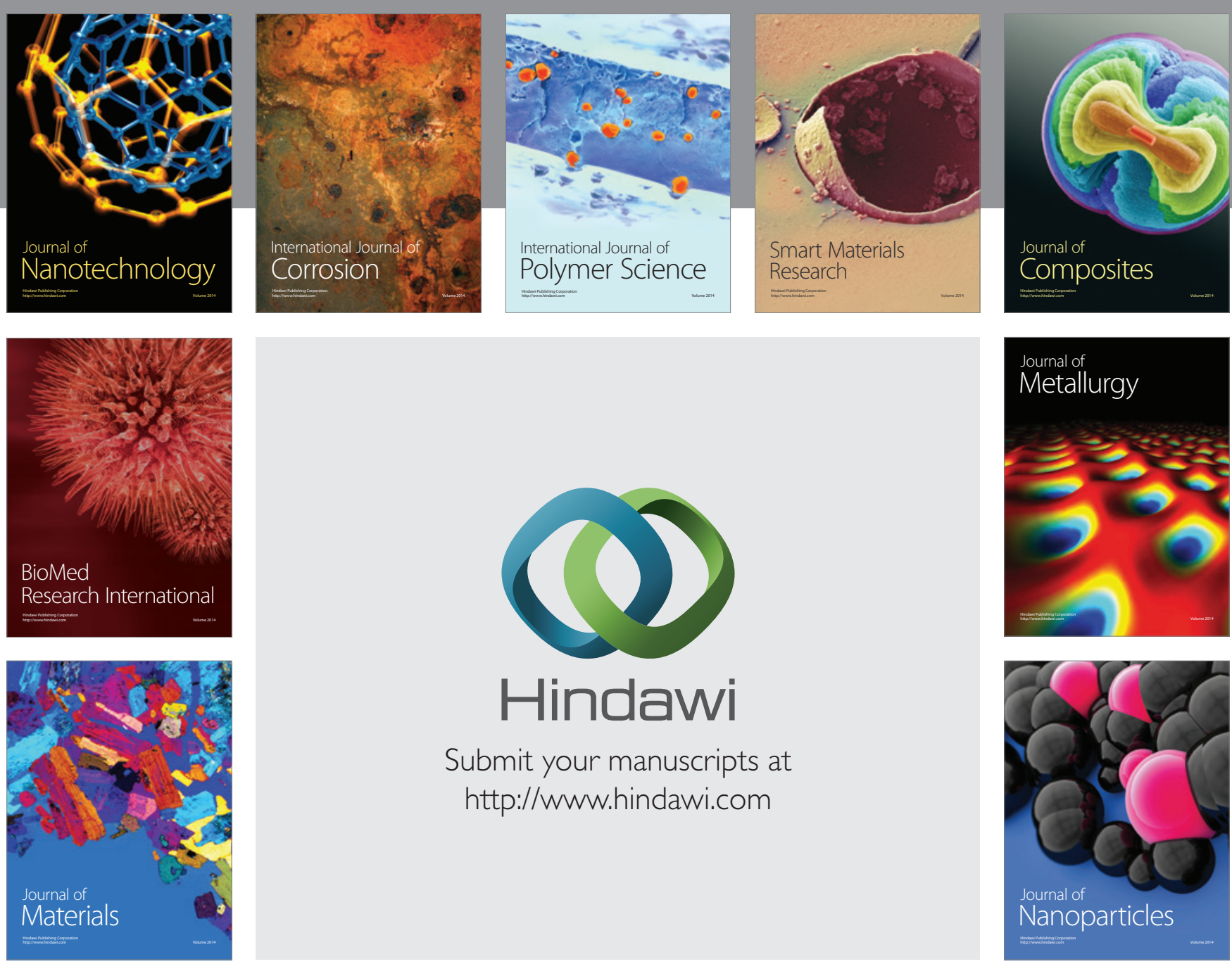

Submit your manuscripts at http://www.hindawi.com
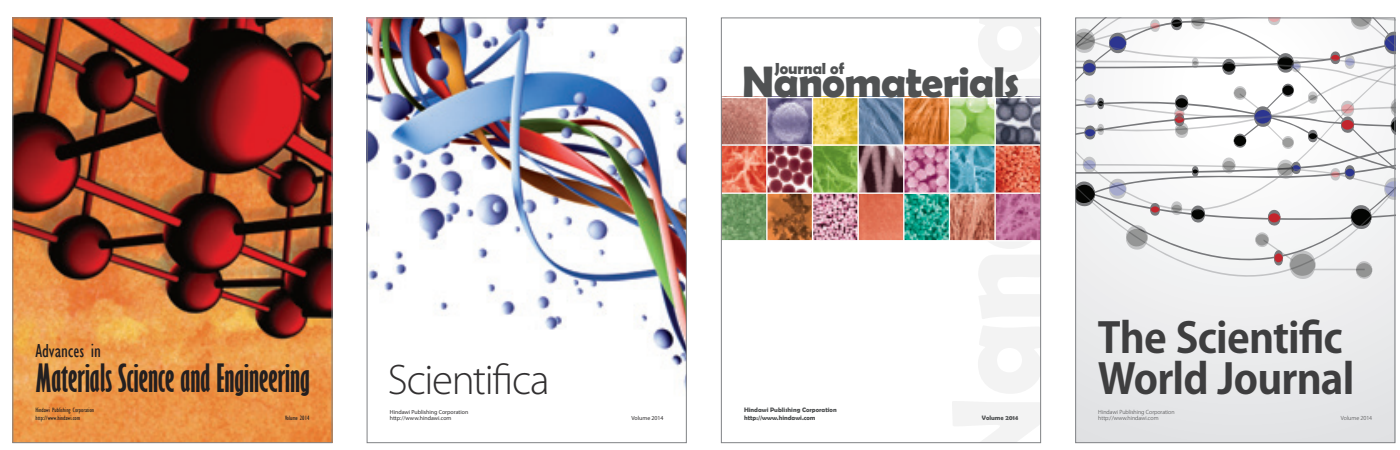

\section{The Scientific World Journal}
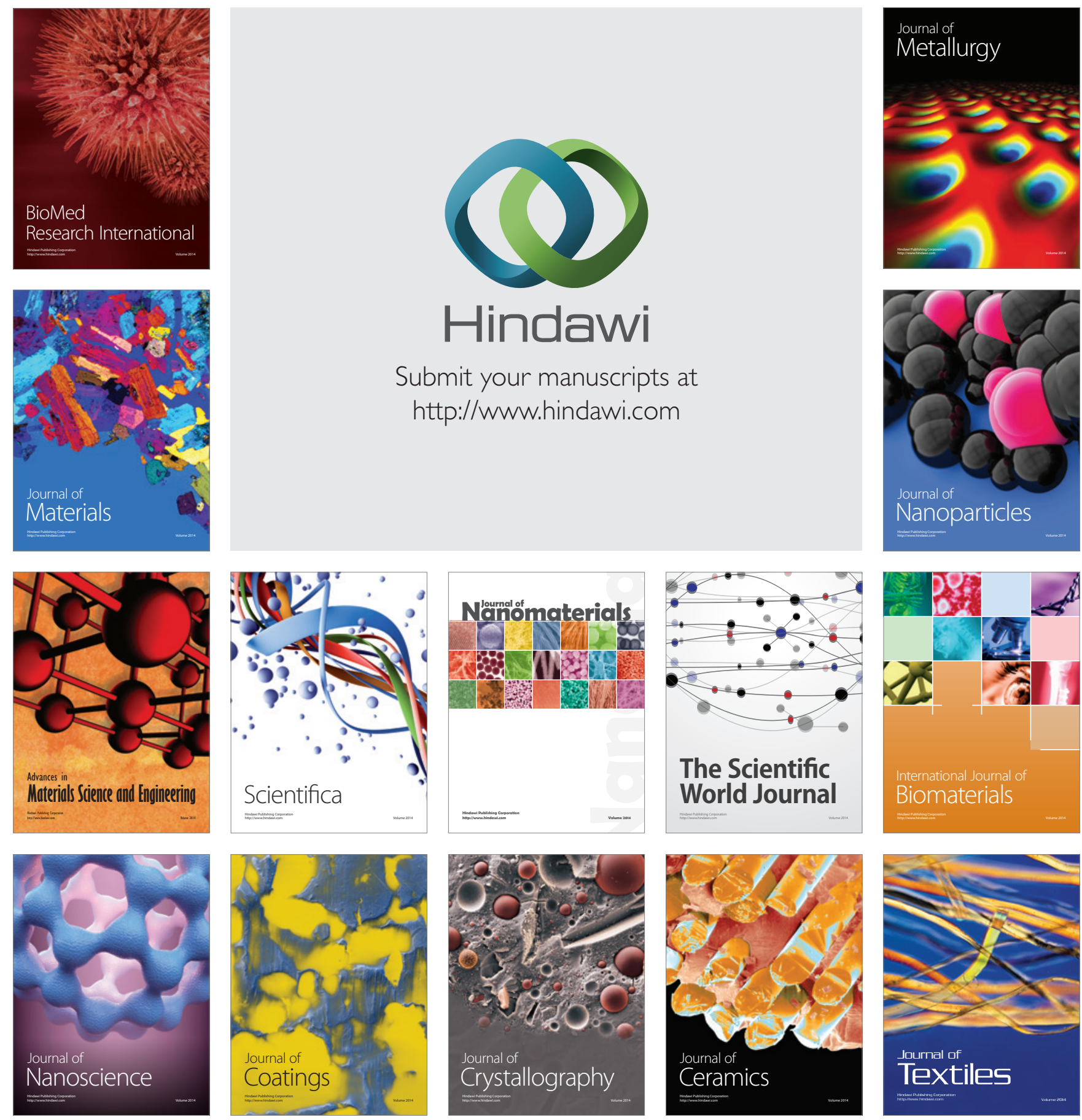